\title{
Dendritic immune cell densities in the central cornea associated with soft contact lens types and lens care solution types: a pilot study
}

This article was published in the following Dove Press journal:

Clinical Ophthalmology

27 March 2012

Number of times this article has been viewed

\author{
Christine W Sindt' \\ Trudy K Grout' \\ D Brice Critser' \\ Jami R Kern ${ }^{2}$ \\ David L Meadows ${ }^{2}$ \\ 'University of lowa Hospitals \\ and Clinics, lowa City, IA; ${ }^{2}$ Alcon \\ Research Ltd, Fort Worth, TX, USA
}

Correspondence: Christine W Sindt Contact Lens Service, Department of Ophthalmology and Visual Science, University of lowa, 200 Hawkins Drive, lowa City, IA 52242-109I, USA

$\mathrm{Tel}+\mathrm{I} 3193564816$

Fax + I 3193560363

Email christine-sindt@uiowa.edu
Background: The purpose of this study was to assess whether differences in central corneal dendritic immune cell densities associated with combinations of soft contact lenses and lens care solutions could be detected by in vivo confocal microscopy.

Methods: Participants were adults naïve to contact lens wear $(n=10)$ or who wore soft contact lenses habitually on a daily-wear schedule $(n=38)$ or on a study-assigned schedule for 30 days with daily disposable silicone hydrogel lenses $(n=15)$. Central corneas were scanned using an in vivo confocal microscope. Cell densities were compared among groups by demographic parameters, lens materials, and lens care solutions (polyhexamethylene biguanide [PHMB], polyquaternium-1 and myristamidopropyl dimethylamine [PQ/MAPD], peroxide, or blister pack solution [for daily disposable lenses]).

Results: Among lens wearers, no associations were observed between immune cell densities and age, gender, or years of lens-wearing experience. Mean cell density was significantly lower $(P<0.01)$ in nonwearers $\left(29 \pm 23\right.$ cells $\left./ \mathrm{mm}^{2}, \mathrm{n}=10\right)$ than in lens wearers (64 \pm 71 cells $\left./ \mathrm{mm}^{2}, \mathrm{n}=53\right)$. Mean cell density was lower $(P=0.21)$ with traditional polymer lenses $\left(47 \pm 44\right.$ cells $\left./ \mathrm{mm}^{2}, \mathrm{n}=12\right)$ than with silicone hydrogel lenses $\left(69 \pm 77\right.$ cells $\left./ \mathrm{mm}^{2}, \mathrm{n}=41\right)$. Lowest to highest mean density of immune cells among lens wearers was as follows: PQ/MAPD solution $\left(49 \pm 28\right.$ cells $\left./ \mathrm{mm}^{2}\right)$, blister pack solution $\left(63 \pm 81\right.$ cells $\left./ \mathrm{mm}^{2}\right)$, PHMB solution $\left(66 \pm 44\right.$ cells $\left./ \mathrm{mm}^{2}\right)$, and peroxide solution $\left(85 \pm 112\right.$ cells $\left./ \mathrm{mm}^{2}\right)$.

Conclusion: In this pilot study, in vivo confocal microscopy was useful for detecting an elevated immune response associated with soft contact lenses, and for identifying lens-related and solution-related immune responses that merit further research.

Keywords: Clear Care, in vivo confocal microscopy, Langerhans, Opti-Free Replenish, ReNu Multi-Plus

\section{Introduction}

Types of immune cells that have been identified in the inflamed corneas of animals and humans include lymphocytes, granulocytes, macrophages, and dendritic cells (including Langerhans-type dendritic cells). ${ }^{1,2}$ Corneal dendritic immune cells are responsible for recognizing and capturing antigens, and for presenting those antigens to $\mathrm{T}$ cells, in order to activate secondary immune responses. ${ }^{3,4}$ The migration of dendritic immune cells from the limbus into the central cornea may be initiated by proinflammatory cytokines or chemokines ${ }^{5,6}$ and may be accomplished via pathways along the nerve plexus. ${ }^{7}$

Only minimal numbers of dendritic immune cells are present in a healthy central cornea, but larger numbers arrive in response to immune or inflammatory challenges. 
Early quantitative analyses of central corneal dendritic immune cells were studies of excised animal tissues, after conditions such as herpetic keratitis ${ }^{8}$ or extended contact lens wear. ${ }^{9}$ More recently, in vivo confocal microscopy has been used to quantify the densities of dendritic immune cells in the central corneas of healthy subjects; ${ }^{2,10}$ of eyes inflamed with keratitis, keratoconjunctivitis, or graft rejection; ${ }^{2}$ of eyes with diabetic neuropathy; ${ }^{11}$ and of eyes of contact lens wearers. ${ }^{12}$ Mean density of central corneal dendritic immune cells has been reported to be approximately $195 \pm 76$ cells $/ \mathrm{mm}^{2}$ in inflamed eyes, ${ }^{2}$ approximately $24 \pm 11$ to $34 \pm 3$ cells $/ \mathrm{mm}^{2}$ in healthy eyes, ${ }^{2,10}$ and approximately $78 \pm 25$ cells $/ \mathrm{mm}^{2}$ in a mixed population of hard and soft contact lens wearers. ${ }^{12}$ In contact lens wearers, the density of dendritic immune cells in the central cornea was found to vary by years of experience with contact lens wear; the immune response was significantly lower in experienced lens wearers $(>10$ years' experience) than in newer lens wearers ( $<5$ years' experience). ${ }^{12}$

Although in vivo confocal microscopy has been used to quantify dendritic immune cells in the conjunctiva ${ }^{13}$ and in the central corneas ${ }^{12}$ of contact lens wearers, no studies as yet have reported the central corneal dendritic immune cell densities with respect to wear of silicone versus traditional hydrogel soft contact lenses, or with respect to use of different lens care solutions. This gap in the literature may be partly due to the labor-intensive and not yet standardized nature of manually analyzing confocal images. The purpose of this study was to use confocal microscopy to examine the numbers of dendritic immune cells in the nerve layers of the corneas of subjects who habitually wore soft contact lenses and who cared for their lenses with various lens care solutions, in order to assess the usefulness of confocal microscopy in this context and to identify any potential immune responses associated with contact lens materials and/or lens care solutions.

\section{Methods}

\section{Enrollment}

Eligible subjects were recruited from adults aged 18 years or older, of either gender and of any race, who presented for a routine examination. Eligible subjects had been wearing traditional polymer hydrogel or silicone hydrogel contact lenses on a daily-wear schedule for at least 2 weeks prior to the qualification examination, or were naïve to contact lens wear. To enter the study, a subject's distance visual acuity was required to be correctable with soft contact lenses to 20/30 Snellen or better in each eye. Exclusion criteria related to the eyes were as follows: one functional eye or a monofit lens; current ocular conditions such as active acute blepharitis, infections, or iritis; any abnormal slit-lamp finding (including blepharitis, meibomian gland disease, conjunctival hyperemia, conjunctival or limbal inflammation, or infection); use of topical ocular medications (prescription or over-the-counter); or any systemic condition with significant ocular side effects that could adversely affect contact lens wear. Sodium fluorescein (Ful-Glo ${ }^{\circledR}$ fluorescein sodium strips; Akorn Inc, Lake Forest, IL) was administered to look for evidence of corneal staining; the location, area, and type of staining were recorded, but staining parameters were not exclusion criteria. All eligible subjects provided informed consent in accordance with the Declaration of Helsinki.

Participant flow of enrolled subjects is shown in Figure 1. Of lens wearers who met all of the enrollment criteria, a subset of 15 subjects (by random assignment) were given a 30-day supply of PureVision ${ }^{\circledR}$ balafilcon A silicone hydrogel contact lenses (Bausch and Lomb, Rochester, NY). These 15 subjects were not assessed for dendritic immune cells

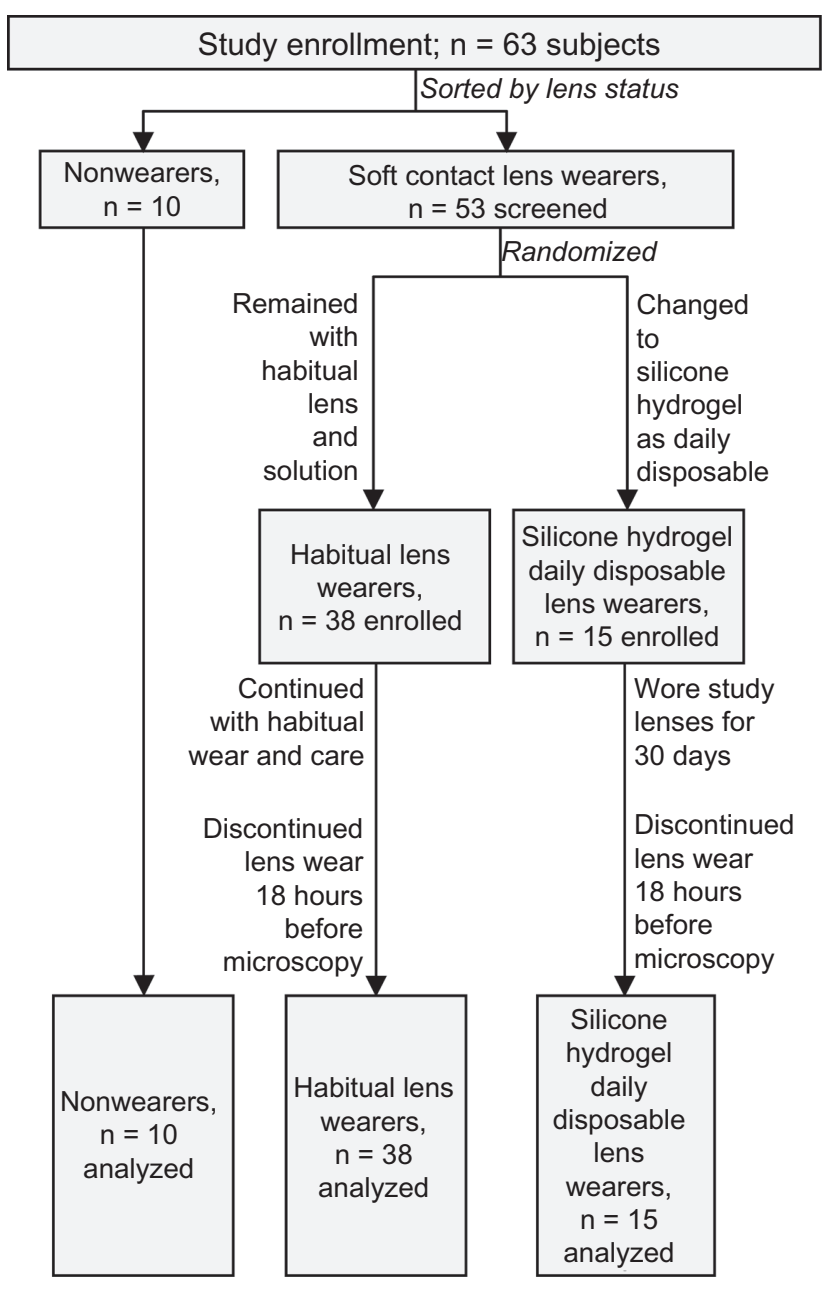

Figure I Disposition of the 63 subjects who participated in the study. 
associated with use of their habitual lenses and solutions, but instead were instructed to discontinue using their habitual lenses and solutions and to use the study lenses as daily disposable lenses, without any lens care solution, for at least one month prior to the next study visit, at which time their corneas would be scanned. Thus, the lens care regimen of 15 subjects was known, but the lens care regimens of the habitual lens wearers were not recorded.

At successful completion of the enrollment visit, a follow-up study visit was scheduled. For evaluation of eyes after habitual use of lens and product, the follow-up visit was scheduled for $\geq 1$ day after the enrollment visit. For evaluation of eyes after wearing the study-distributed daily disposable silicone hydrogel lenses, the follow-up visit was scheduled for 30 days after the enrollment visit. All subjects were instructed to discontinue wearing their habitual contact lenses or study-distributed daily disposable silicone hydrogel lenses at least 18 hours prior to the study appointment.

\section{Corneal assessments}

At the study visit, each enrolled subject arrived without lenses inserted, and eligibility criteria were reverified. A central corneal scan was taken with a Heidelberg Retina Tomograph Rostock Cornea Module (HRT/RCM; Heidelberg Engineering $\mathrm{GmbH}$, Heidelberg, Germany). The light source was a $670 \mathrm{~nm}$ diode laser (Class 1) with $1 \mu \mathrm{m}$ resolution. Images were captured with an area of $400 \mu \mathrm{m}$ by $400 \mu \mathrm{m}$ and a digital image size of 384 by 384 pixels. Each volume scan captured a series of 40 images, in $2 \mu \mathrm{m}$ increments, yielding an $80 \mu \mathrm{m}$ stack of images. The ophthalmic photographer captured at least four volume scans per eye; extra scans were captured if alignment problems were encountered or suspected.

\section{Image and data analysis}

Image analyses were conducted by a single investigator in a masked fashion. Volume scans were evaluable only if they had been captured at an axis that was perpendicular to the surface of the cornea. Volume scans were excluded from analysis if they had captured images from an angle that was oblique to the surface of the cornea. Oblique scans were identified by the presence of different types of cells, representing different layers of cells, appearing in different areas of the same image.

In each evaluable volume scan, the subbasal nerve plexus layer was identified by morphology and by approximate depth in the volume scan; the nerve plexus usually can be found approximately $60 \mu \mathrm{m}$ posterior to the surface of the cornea. ${ }^{14}$ The nerve plexus generally spans a depth of 1-3 scans, or a thickness of 2-6 $\mu \mathrm{m}$. When the nerve plexus layer spanned multiple images in a volume scan, dendritic immune cells were counted in the image that had the clearest nerve definition. Dendritic immune cells were tagged in the image by the investigator, who used best clinical experience to identify dendritic immune cells on the basis of parameters such as their brightness and morphology (see Figure 2). The HRT/RCM software then divided the number of the tagged cells by the area of the image $\left(0.16 \mathrm{~mm}^{2}\right)$ to yield the density of cells. Cells in each evaluable image were counted twice, independently, by the same investigator at two different times; all confirmation counts matched original counts. Where available, multiple results from multiple volume scans were averaged per eye; thereafter, results from both eyes were averaged together, before averaging per study group.

Data were compared among groups by lens type and lens care solution type, by duration of experience with lens wear, by gender, and by age. Durations of experience with contact lens wear, categories of cell densities, and subject ages were sorted into similar categories as were presented in a similar study. ${ }^{12}$ As previously described, ${ }^{12}$ experience categories were as follows: less than 5 years, 5-10 years, and more than 10 years. As previously described, ${ }^{12}$ cell density categories were as follows: $\leq 64$ cells $/ \mathrm{mm}^{2}$ for "low/moderate" density, and $>64$ cells $/ \mathrm{mm}^{2}$ for

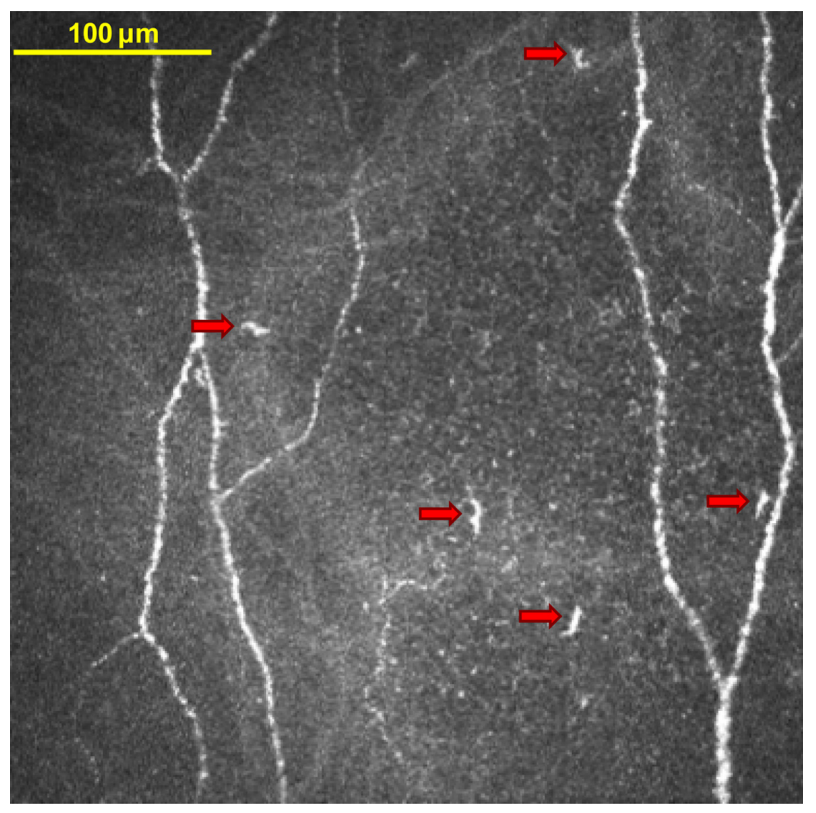

Figure 2 In vivo confocal microscopy image of dendritic immune cells in the central cornea. This image is from a study participant who habitually wore silicone hydrogel soft contact lenses and who used a polyquaternium-I and myristamidopropyl dimethylamine solution to care for the lenses. The five features that are marked by arrows were tagged by the investigator as dendritic immune cells. 
"elevated" density. The low/moderate density category represented $\leq 4$ cells per $0.0625 \mathrm{~mm}^{2}$ image in the previous study, ${ }^{12}$ and represented approximately $\leq 5$ per $0.16 \mathrm{~mm}^{2}$ image in the current study. As previously described, ${ }^{12}$ age categories were as follows: $<30$ years, 30-50 years, and $>50$ years. Results are presented as mean \pm standard deviation in text and as the mean $\pm 95 \%$ confidence interval in figures. Statistical differences were investigated by a two-sided, unpaired $t$-test for continuous variables and by Chi-square for categorical variables.

\section{Results}

\section{Population characteristics}

A total of 63 subjects (126 eyes) were evaluated, ie, 10 subjects who were naïve to lens wear, 38 subjects in the habitual use group (including habitual daily disposable traditional polymer hydrogel lens wearers), and 15 subjects in the study-distributed daily disposable silicone hydrogel group. The baseline characteristics, sorted by habitual lens care solution and habitual lens type, are shown in Table 1. Among habitual wearers of traditional polymer hydrogel lenses, lens brands included Acuvue ${ }^{\circledR}$ types (Johnson and Johnson), Soflens $^{\circledR} 38$ (Bausch and Lomb), Biomedics ${ }^{\circledR}$ (American Hydron), Dailies (Ciba Vision), Frequency ${ }^{\circledR} 5$ (CooperVision), Freshlook ${ }^{\circledR}$ Daily (Ciba Vision), and Proclear $^{\circledR}$ (Cooper Vision). Among habitual wearers of silicone hydrogel lenses, lens brands included Acuvue ${ }^{\circledR}$ Advance $^{\circledR}$ and Oasys ${ }^{\circledR}$ (Johnson and Johnson), Biofinity ${ }^{\circledR}$ (CooperVision), PureVision ${ }^{\circledR}$ (Bausch and Lomb), Focus ${ }^{\circledR}$ Night and Day (Ciba Vision), and O2 Optix ${ }^{\circledR}$ (Ciba Vision). All habitual users of peroxide care solution used ClearCare ${ }^{\circledR}$ (Ciba Vision) and all habitual users of PQ/MAPD solution used Opti-Free ${ }^{\circledR}$ Replenish ${ }^{\circledR}$ Multi-Purpose Disinfecting Solution (Alcon). Among habitual users of PHMB solutions, brands included Aquify ${ }^{\circledR}$ (Ciba Vision), Complete ${ }^{\circledR}$ Multi-Purpose Solution Easy Rub ${ }^{\circledR}$ Formula (Abbott Medical Optics), ReNu MultiPlus ${ }^{\circledR}$ (Bausch and Lomb), and generic or store brands.

\section{Image evaluation}

Of the 126 eyes, 124 had at least one evaluable image. For those 124 eyes, the average number of evaluable images was $2.5 \pm 1.0$ (range, 1-5) images, with 22 eyes having one evaluable image and 102 eyes having more than one evaluable image. Of the 63 subjects, all had at least one evaluable image. For those 63 subjects, the average number was $4.9 \pm 1.8$ evaluable (range, 1-9) images, with 62 of 63 subjects having more than one evaluable image.

\section{Immune cell density and demographic parameters}

The average age of the group was $37 \pm 14$ (range 18-75) years. Lens wearers in the youngest age group, at less than 30 years of age $(n=23)$, had cell densities of $48 \pm 38$ cells $/ \mathrm{mm}^{2}$ ( $P=0.13$ versus central age group; $P=0.67$ versus oldest age group). Lens wearers in the central age group, at age 30-50 years $(\mathrm{n}=22)$, had cell densities of $41 \pm 6$ cells $/ \mathrm{mm}^{2}(P=0.13$ versus the youngest group; $P=0.35$ versus the oldest group). Lens wearers in the oldest age group, at older than 50 years of age $(\mathrm{n}=8)$, had cell densities of $57 \pm 49$ cells $/ \mathrm{mm}^{2}(P=0.67$ versus the youngest group; $P=0.35$ versus the central group).

The overall population was $90.5 \%$ female $(n=57)$ and $9.5 \%$ male $(n=6)$. The small number of men limited the ability to detect corneal responses related to gender or to combinations of gender and age. Mean immune cell density was $P=0.85$ between lens-wearing women $\left(39 \pm 71\right.$ cells $/ \mathrm{mm}^{2}$, $\mathrm{n}=47)$ and lens-wearing men $\left(69 \pm 72\right.$ cells $\left./ \mathrm{mm}^{2}, \mathrm{n}=6\right)$. All of the subjects naïve to lens wear in the study $(n=10)$ were women.

\section{Immune cell density and experience with lens wear}

Of the 53 subjects who wore lenses before participating in the study, 51 subjects had information on file for years of experience with contact lens wear, as shown in Table 2. Mean duration of experience was $14 \pm 11$ years. Duration of lens-wearing experience was similar $(P=0.95)$ between the silicone hydrogel lens

Table I Numbers of subjects in each group, sorted by habitual lens care solution and habitual lens type

\begin{tabular}{lllll}
\hline $\begin{array}{l}\text { Lens care solution, } \\
\mathbf{n}(\%)\end{array}$ & $\mathbf{N}$ Nonwearers, & $\begin{array}{l}\text { Traditional hydrogel } \\
\text { wearers, } \mathbf{n = 1 2}\end{array}$ & $\begin{array}{l}\text { Silicone hydrogel } \\
\text { wearers, } \mathbf{n}=\mathbf{4 1}\end{array}$ & $\begin{array}{l}\text { Total, } \\
\mathbf{n}=\mathbf{6 3}\end{array}$ \\
\hline None & $10(16 \%)$ & - & - & $10(16 \%)$ \\
Blister pack & - & $3(5 \%)$ & $15(24 \%)$ & $18(29 \%)$ \\
PQ/MAPD & - & $3(5 \%)$ & $1 \mathrm{I}(17 \%)$ & $14(22 \%)$ \\
PHMB & - & $4(6 \%)$ & $7(11 \%)$ & $11(17 \%)$ \\
Peroxide & - & $2(3 \%)$ & $8(13 \%)$ & $10(16 \%)$ \\
\hline
\end{tabular}

Note: All lens wearers were on a daily-wear schedule (no extended-wear users).

Abbreviations: PHMB, polyhexamethylene biguanide; PQ/MAPD, polyquaternium-I and myristamidopropyl dimethylamine. 
Table 2 Experience with contact lens wear for 51 of the 53 subjects who wore lenses at the time of entering the study (no history was available for two lens wearers)

\begin{tabular}{|c|c|c|}
\hline & $\begin{array}{l}\text { Experience with } \\
\text { lens wear, years }\end{array}$ & $\begin{array}{l}\mathbf{n} \text { (with data available) } \\
\text { of } \mathbf{n} \text { (in study) }\end{array}$ \\
\hline \multicolumn{3}{|c|}{ Per lens type, mean \pm SD } \\
\hline Traditional lenses & $14 \pm 13$ & 12 of 12 \\
\hline Silicone lenses & $14 \pm 10$ & 39 of 41 \\
\hline \multicolumn{3}{|c|}{ Per care solution, mean \pm SD } \\
\hline Blister pack & $14 \pm 9$ & 18 of 18 \\
\hline PQ/MAPD & $10 \pm 6$ & 13 of 14 \\
\hline PHMB & $16 \pm 11$ & 10 of 11 \\
\hline Peroxide & $19 \pm 15$ & 10 of 10 \\
\hline
\end{tabular}

Note: Categories denote lenses and solutions that were used at time of analysis; lenses and solutions used before entry into the study may have varied.

Abbreviations: $\mathrm{PHMB}$, polyhexamethylene biguanide; $\mathrm{PQ} / \mathrm{MAPD}$, polyquaternium-I and myristamidopropyl dimethylamine; SD, standard deviation.

group and the traditional polymer hydrogel lens group, and were statistically similar between all pairwise comparisons of lens care solution groups. When sorted into lens wear experience categories, mean immune cell density was statistically similar $(P>0.43)$ among categories: subjects with 5 years or less of experience had cell densities of $49 \pm 52$ cells $/ \mathrm{mm}^{2}(\mathrm{n}=7)$, subjects with 5-10 years of experience had cell densities of $73 \pm 92$ cells $/ \mathrm{mm}^{2}(\mathrm{n}=16)$, and subjects with $>10$ years of experience had cell densities of $62 \pm 65$ cells $/ \mathrm{mm}^{2}(\mathrm{n}=28)$.

\section{Immune cells associated with lens materials}

Subjects who wore lenses had a mean immune cell density of $64 \pm 71 \mathrm{cells} / \mathrm{mm}^{2}$, which was significantly higher $(P<0.01)$ than the density in subjects who were naïve to lens wear $\left(29 \pm 23\right.$ cells $\left./ \mathrm{mm}^{2}\right)$, as shown in Table 3. When categorized into immune cell density levels ( $\leq 64$ cells $/ \mathrm{mm}^{2}$ for "low/ moderate" density, and $>64$ cells $/ \mathrm{mm}^{2}$ for "elevated" density), the Chi-square distribution was $P=0.11$ between lens wearers and nonwearers. The mean immune cell density was lower with traditional polymer hydrogel lenses $\left(47 \pm 44 \mathrm{cells} / \mathrm{mm}^{2}\right)$ than with silicone hydrogel lenses $\left(69 \pm 77\right.$ cells $\left./ \mathrm{mm}^{2}\right)$; the smaller number of subjects in the traditional polymer hydrogel group $(n=12)$ than in the silicone hydrogel group $(\mathrm{n}=41)$ limited the ability to detect statistical differences $(P=0.21)$.

When the six men in the study population were excluded from this analysis, the same trend in mean immune cell density was observed, ie, least in nonwearers, intermediate with conventional lenses, and highest with silicone hydrogel lenses. Values were $29 \pm 23$ cells $/ \mathrm{mm}^{2}$ among nonwearing women $(\mathrm{n}=10), 51 \pm 45$ cells $/ \mathrm{mm}^{2}$ among women who wore conventional lenses $(\mathrm{n}=9)$, and $66 \pm 76$ cells $/ \mathrm{mm}^{2}$ among women who wore silicone hydrogel lenses $(n=38)$.

\section{Immune cells associated with lens care solutions}

When subjects were sorted by their lens care solution (or lack thereof), some trends and significant differences were observable in mean cell densities, as shown in Figure 3A. The trend from lowest to highest mean density of immune cells was as follows: nonwearers $\left(29 \pm 23\right.$ cells $\left./ \mathrm{mm}^{2}\right), \mathrm{PQ} / \mathrm{MAPD}$ solution $(49 \pm 28$ cells/ $\mathrm{mm}^{2}, P=0.08$ versus nonwearers), blister pack solution (63 \pm 81 cells $/ \mathrm{mm}^{2}, P=0.12$ versus nonwearers), PHMB solution ( $66 \pm 44$ cells $/ \mathrm{mm}^{2}, P=0.03$ versus nonwearers), and peroxide solution $\left(85 \pm 112\right.$ cells $/ \mathrm{mm}^{2}, P=0.16$ versus nonwearers). No significant pairwise differences were detected among solution subgroups (all $P \geq 0.27$ ). Variability in immune cell density was largest in the peroxide solution group, ranging from 1 to 370 cells per $\mathrm{mm}^{2}$.

Trends also were observable in immune cell density categories (see Figure 3B), but no significant differences were observable (all $P \geq 0.07$ by Chi-square). The trend from small-

Table 3 Immune cell densities by lens material (or lack thereof)

\begin{tabular}{|c|c|c|c|c|}
\hline \multirow[t]{2}{*}{ Immune cell density } & \multirow{2}{*}{$\begin{array}{l}\text { Nonwearers } \\
n=10\end{array}$} & \multicolumn{3}{|l|}{ Lens wearers } \\
\hline & & Traditional hydrogel, $n=12$ & Silicone hydrogel, ${ }^{a} n=4 I$ & Overall group, $n=53$ \\
\hline \multicolumn{5}{|l|}{ Values } \\
\hline Mean $\pm S D$ & $29 \pm 23$ & $47 \pm 44$ & $69 \pm 77^{*, b}$ & $64 \pm 7 I^{*}$ \\
\hline Range (min - max) & $(3-7 I)$ & $(4-137)$ & $(I-370)$ & $(I-370)$ \\
\hline \multicolumn{5}{|l|}{ Categories } \\
\hline Low/moderate, n (\%) & $9(90 \%)$ & $8(67 \%)$ & $26(63 \%)$ & $34(64 \%)$ \\
\hline Elevated, n (\%) & I (I0\%) & $4(33 \%)$ & $15(37 \%)$ & $19(36 \%)$ \\
\hline Chi-square vs nonwearers & - & $P=0.19$ & $P=0.10$ & $P=0.11$ \\
\hline
\end{tabular}

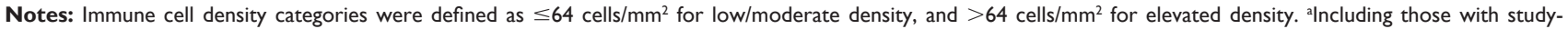
distributed daily disposable silicone hydrogel lenses; ${ }^{b} P=0.21$ by $t$-test versus HEMA hydrogel. $* P<0.01$ by $t$-test versus nonwearers.

Abbreviation: SD, standard deviation. 
Overall population: nonwearers, conventional lens wearers, and silicone hydrogel lens wearers
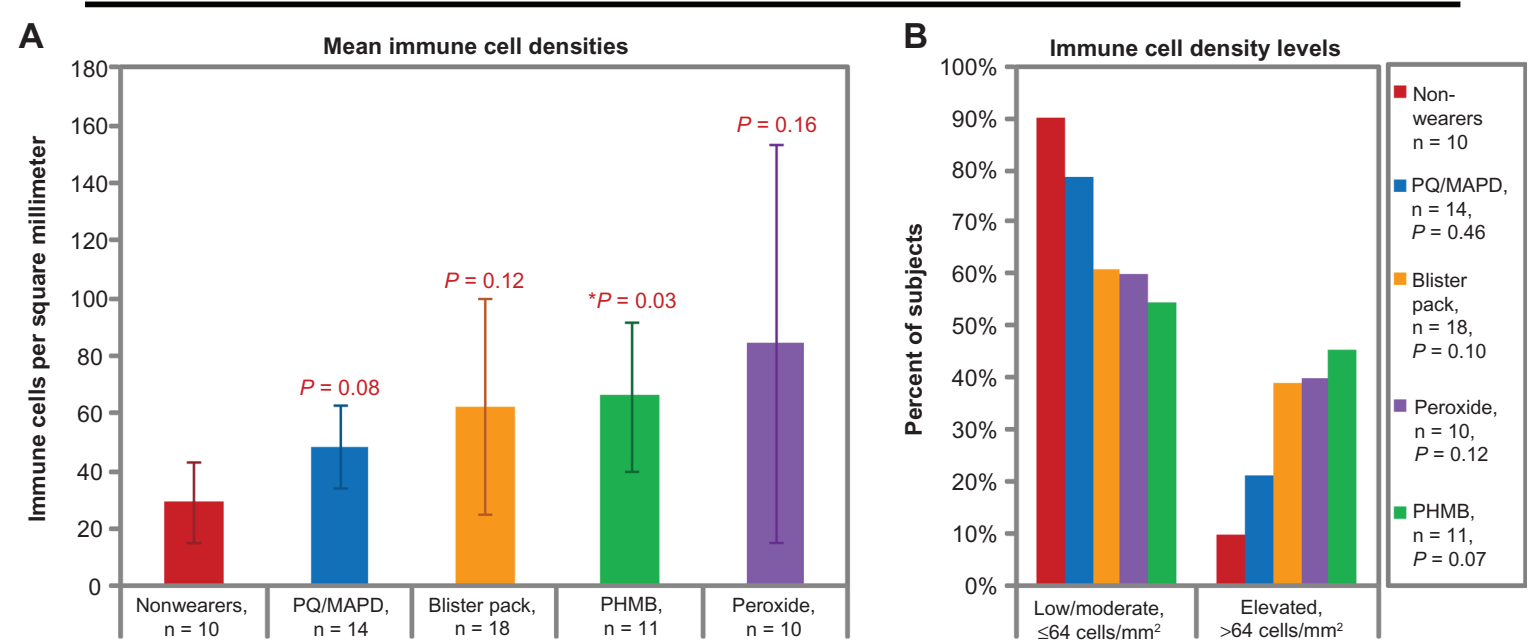

Figure 3 Central corneal dendritic immune cell densities of the overall study population, grouped by habitual or study-assigned lens care solution. (A) Mean immune cell densities. Bars represent means and error bars represent $95 \%$ confidence intervals. $P$ values by $t$-test versus nonwearers are shown for each lens-wearing group. (B) Immune cell density levels. $P$ values by Chi-square versus nonwearers are shown in the legend.

Note: Blister pack = daily disposables.

Abbreviations: PHMB, polyhexamethylene biguanide; PQ/MAPD, polyquaternium-I and myristamidopropyl dimethylamine.

est to largest proportion of subjects with elevated cell densities was as follows: nonwearers ( $10 \%$ of subjects with elevated cell densities), PQ/MAPD users (21\%), blister pack users (39\%), peroxide users (40\%), and PHMB users (45\%).

\section{Immune cells associated \\ with combinations of lens materials}

\section{and solutions}

When subjects were sorted by the combination of their lens material and their lens care solution, some trends and significant differences were observed in the dendritic immune cell densities of silicone hydrogel lens wearers, as shown in Figure 4. Within the silicone hydrogel lens group, the trend from lowest to highest mean density of immune cells was as follows: nonwearers $\left(29 \pm 23\right.$ cells $\left./ \mathrm{mm}^{2}\right), \mathrm{PQ} / \mathrm{MAPD}$ solution $(55 \pm 25$ cells/ $\mathrm{mm}^{2}, P=0.02$ versus nonwearers), blister pack solution (64 \pm 85 cells $/ \mathrm{mm}^{2}, P=0.16$ versus nonwearers), PHMB solution (77 \pm 45 cells $/ \mathrm{mm}^{2}, P=0.03$ versus nonwearers), and peroxide solution $\left(90 \pm 124\right.$ cells $/ \mathrm{mm}^{2}, P=0.21$ versus

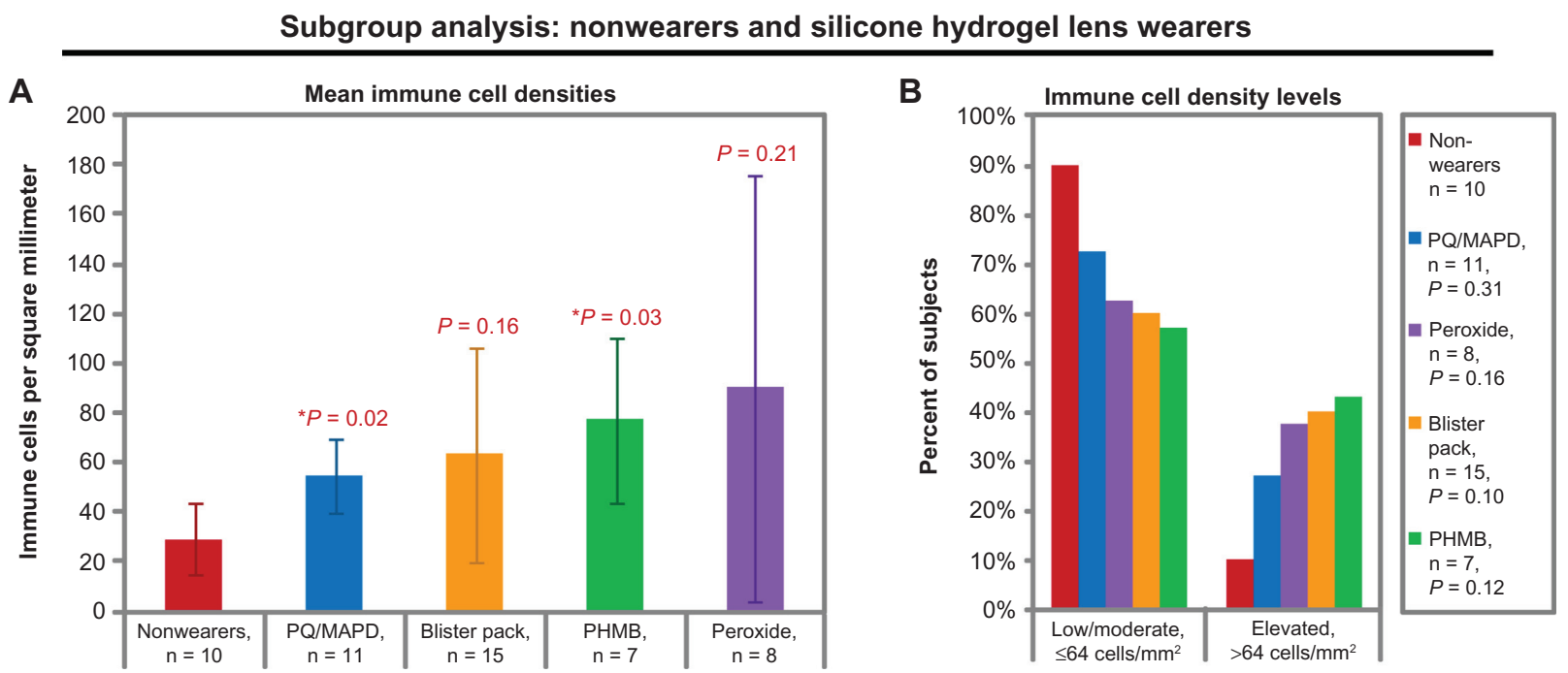

Figure 4 Central corneal dendritic immune cell densities of the nonwearers and of the silicone hydrogel lens wearers, grouped by habitual or study-assigned lens care solution. (A) Mean immune cell densities. Bars represent means and error bars represent $95 \%$ confidence intervals. $P$-values by $t$-test versus nonwearers are shown for each lens-wearing group. (B) Immune cell density levels. $P$-values by chi-square versus nonwearers are shown in the legend.

Note: Blister pack = daily disposables.

Abbreviations: PHMB, polyhexamethylene biguanide; PQ/MAPD, polyquaternium-I and myristamidopropyl dimethylamine. 
nonwearers). No significant pairwise differences could be detected among combinations of solutions and silicone hydrogel lenses (all $P \geq 0.27$ ).

The traditional polymer hydrogel lens subgroups were too small (2-4 subjects per solution type) to detect any statistical differences in mean values, but it was noted that all mean densities were numerically lower in the traditional polymer hydrogel lens plus solution combination subgroups than in their comparator silicone hydrogel plus solution combination subgroups.

\section{Discussion}

This study is among the earliest published reports that describe the use of in vivo confocal microscopy to evaluate dendritic immune cell densities in the central corneas of contact lens wearers. As expected, the density of dendritic immune cells was significantly higher $(P<0.01)$ in the central corneas of lens wearers than of nonwearers. Unlike a comparable study, ${ }^{12}$ our results indicated no significant differences or trends in cell densities associated with years of experience with lens wear or with age of lens wearers; see Table 4 for a comparison of the two studies. Instead, we found possible differences in association with lens materials and lens care solutions, which are parameters that have not previously been reported and that merit further investigation in larger-scale studies.

The densities of dendritic immune cells that were found in this study were within expected ranges. For healthy control eyes, dendritic immune cell densities reported in the literature had a mean of 24-34 cells per square $m m,{ }^{2,10}$ a range that is in accordance with the immune cell density that was found in this study (mean $29 \pm 23$ cells $/ \mathrm{mm}^{2}$ in the subjects who did not wear lenses). For contact lens wearers, central corneal dendritic immune cell densities have been reported in only one study in the literature. ${ }^{12}$ That study evaluated an unspecified mixture of traditional polymer hydrogel and silicone hydrogel lens wearers, who used an unspecified variety of lens care solutions, and reported that the average density of dendritic (Langerhans) cells in the central cornea of soft contact lens wearers was $114 \pm 41$ cells $/ \mathrm{mm}^{2}{ }^{12}$ That literature value is similar to the result for mixed-type lenses in the peroxide solution group in the current study $\left(85 \pm 112\right.$ cells $\left./ \mathrm{mm}^{2}\right)$, but appears to be higher than the result for mixed-type lenses in the PQ/MAPD solution group in the current study $\left(49 \pm 28\right.$ cells $\left./ \mathrm{mm}^{2}\right)$. The relative consistencies of the findings of our pilot study with those that are available in the literature confirm the validity of in vivo confocal microscopy for this purpose.

One interesting observation in this preliminary study was that the mean dendritic immune cell density was higher with silicone hydrogel lenses $\left(69 \pm 77\right.$ cells $\left./ \mathrm{mm}^{2}\right)$ than with traditional polymer hydrogel lenses $\left(47 \pm 44\right.$ cells $\left./ \mathrm{mm}^{2}\right)$; however, the small number of subjects in the traditional polymer hydrogel group $(n=12)$ limited the ability to detect statistical differences $(P=0.21)$. Immune responses to silicone hydrogel lens materials may be caused by chemical effects, mechanical effects, or both, since silicone hydrogel lenses differ from traditional polymer lenses in so many ways. Compared with traditional polymer hydrogel lenses, silicone hydrogel lenses reduce the incidence of complications related

Table 4 Apparent differences in demographic-related findings: current study of soft contact lens wearers versus a previous study with a mixed population of soft and hard contact lens wearers ${ }^{12}$

\begin{tabular}{|c|c|c|c|c|}
\hline & \multicolumn{4}{|c|}{ Central corneal immune cell density } \\
\hline & \multicolumn{2}{|c|}{ Current study, $n=53$ lens wearers } & \multicolumn{2}{|c|}{ Study by Zhivov et $\mathrm{al}^{\prime 2}, \mathrm{n}=55$ lens wearers } \\
\hline & $\mathbf{n}$ & Cells $/ \mathrm{mm}^{2}$, mean \pm SD & $\mathbf{n}$ & Cells $/ \mathbf{m m}^{2}$, mean \pm SEM \\
\hline \multicolumn{5}{|c|}{ Experience with lens wear ${ }^{a}$} \\
\hline$<5$ years & 7 & $49 \pm 52$ & $\mathrm{n} / \mathrm{r}$ & $144 \pm 58$ \\
\hline $5-10$ years & 26 & $73 \pm 92$ & $\mathrm{n} / \mathrm{r}$ & $122 \pm 58$ \\
\hline$>10$ years & 28 & $62 \pm 65$ & $\mathrm{n} / \mathrm{r}$ & $15 \pm 5$ \\
\hline \multicolumn{5}{|c|}{ Lens wearer age } \\
\hline$<30$ years & 23 & $48 \pm 38$ & 19 & $130 \pm 60$ \\
\hline $30-50$ years & 22 & $41 \pm 6$ & 29 & $40 \pm 25$ \\
\hline$>50$ years & 8 & $57 \pm 49$ & 10 & $80 \pm 55$ \\
\hline \multicolumn{5}{|l|}{ Lens wearer sex } \\
\hline Men & $6^{\mathrm{b}}$ & $69 \pm 72$ & 16 & $52 \pm 36$ \\
\hline Women & 47 & $39 \pm 71$ & 39 & $90 \pm 31$ \\
\hline
\end{tabular}

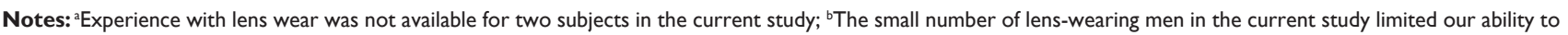
investigate age/sex interactions that were reported by the reference study.

Abbreviations: SD, standard deviation; SEM, standard error of the mean; n/r, not reported in study by Zhivov et al ${ }^{12}$. 
to hypoxia, ${ }^{15}$ but do not reduce the incidence of microbial keratitis, ${ }^{16}$ and have been associated with increased risk for inflammatory events ${ }^{17}$ and other types of adverse events. ${ }^{18}$ Our results indicate that larger-scale and better controlled studies of the central corneal immune cell densities in silicone hydrogel lens wearers versus traditional polymer hydrogel lens wearers are needed.

One notable finding of the current study was that users of peroxide solution had the highest and most variable density of central corneal dendritic immune cells. Peroxide solutions may be associated with variable and elevated immune responses for a variety of reasons. Some clinicians believe that peroxide solutions can offer a reduced amount of irritation because peroxide solutions lack preservatives; thus, some practitioners may recommend peroxide solutions to contact lens wearers who report intolerance issues when using preserved solutions. ${ }^{19}$ That is, peroxide solutions may be prescribed to "problem" patients. In this study, no subjects reported experiencing intolerance issues at the time of the examination, but we did not query whether subjects had been switched to a peroxide solution in their past because of a previous intolerance issue that may have indicated an elevated corneal susceptibility. Alternatively (or in addition), the elevated immune response observed in this study could have been due to disadvantages that are possible with peroxide solutions, such as incomplete neutralization of the solution before insertion of the lens into the eye, or lack of continued preservation after disinfection is complete. ${ }^{19}$ Given these preliminary findings, we believe that immune reactions in the corneas of users of peroxide lens care solutions should be investigated more thoroughly.

This study also demonstrated that wearers of silicone hydrogel lenses conditioned with PHMB solutions had a significantly elevated density of dendritic immune cells ( $P=0.03$ versus nonwearers), second only to the elevation observed with peroxide solutions. This finding may be related to the previously reported undesirable interactions between silicone hydrogel lenses and these types of multipurpose conditioning solutions. ${ }^{20-22}$ In acute studies (2-hour studies) $)^{20,21}$ and in a longer-term (1-month) study, ${ }^{22}$ silicone hydrogel lenses that were conditioned with PHMB-preserved solutions resulted in excessive corneal staining, while silicone hydrogel lenses conditioned with peroxide solutions or PQ/MAPD solutions resulted in minimal corneal staining. Similarly, silicone hydrogel lenses in combination with PHMB solutions have been found to induce fluorescein penetration through the cornea at a rate ratio that was significantly higher than the rate ratio associated with $\mathrm{PQ} / \mathrm{MAPD}$ solution and silicone hydrogel lenses. ${ }^{23}$ Laboratory and clinical studies have indicated that silicone hydrogel lenses absorbed biocides (like PHMB and alexidine) during soaking, ${ }^{24-26}$ and then released the biocides into the eye during lens wear. ${ }^{27}$ Beyond the effect of disinfectants on the lens material, other ingredients in the lens care solution, such as surfactants or buffers, may change the interactions between a silicone hydrogel lens and the cornea. ${ }^{28}$ Interactions are very complex between silicone hydrogel lenses, their care solutions, and the corneas of their wearers, and merit further investigation.

This study had many limitations, including a design that was a mix of prospective and cross-sectional; a small number of subjects in each group; a population in which men represented only $9.5 \%$ of lens wearers and $0 \%$ of nonwearers; and a large number of unknown variables, such as adherence to lens care regimens and duration of lens wear per day. Larger numbers of subjects may have allowed detection of more differences that were statistically significant; however, manual cell counting is so time-consuming that large-scale studies may be impractical until software-based analysis options become available. Larger numbers of subjects also may have allowed us to investigate factors that could have contributed to the observed variability in dendritic immune cell density in some groups; such variability-inducing factors could have included compliance with care regimens, duration of lens wear per day, and gender. The current study could have benefitted further from the addition of an established measure of corneal health (such as corneal staining) to compare with this investigational measure of corneal health (dendritic immune cell density).

\section{Conclusion}

This study found that in vivo confocal microscopy was a useful (though laborious) technique to evaluate dendritic immune cell densities in the central corneas of soft contact lens wearers and to detect possible differences in corneal responses associated with different types of lens materials and lens care solutions. The results of this study should be useful in guiding future investigations into the impact of soft contact lens materials and lens care solutions on the cornea. While previous work has identified age, gender, and experience with lens wear as important factors contributing to the immune response in the central cornea, our study indicates that lens type and lens care solution are also contributing factors. Given that these subject-related, lens-related, and solution-related variables may affect central corneal dendritic cell density, all of these variables should be controlled in confocal studies of the corneas of soft contact lens wearers. 
Further study is needed to elucidate the interrelated nature of these variables.

\section{Disclosure}

Alcon funded this study and provided the assistance of an Alcon-employed medical writer. JRK and DLM are employees of Alcon. CWS is a consultant to Alcon.

\section{References}

1. Shimeld C, Whiteland JL, Nicholls SM, Easty DL, Hill TJ. Immune cell infiltration in corneas of mice with recurrent herpes simplex virus disease. J Gen Virol. 1996;77:977-985.

2. Mastropasqua L, Nubile M, Lanzini M, et al. Epithelial dendritic cell distribution in normal and inflamed human cornea: in vivo confocal microscopy study. Am J Ophthalmol. 2006;142:736-744.

3. Hamrah P, Zhang Q, Liu Y, Dana MR. Novel characterization of MHC class II-negative population of resident corneal Langerhans cell-type dendritic cells. Invest Ophthalmol Vis Sci. 2002;43:639-646.

4. Yamagami S, Yokoo S, Usui T, Yamagami H, Amano S, Ebihara N. Distinct populations of dendritic cells in the normal human donor corneal epithelium. Invest Ophthalmol Vis Sci. 2005;46:4489-4494.

5. Dekaris I, Zhu SN, Dana MR. TNF-\{alpha $\}$ regulates corneal Langerhans cell migration. J Immunol. 1999;162:4235-4239.

6. Yamagami S, Hamrah P, Miyamoto K, et al. CCR5 chemokine receptor mediates recruitment of MHC class II-positive Langerhans cells in the mouse corneal epithelium. Invest Ophthalmol Vis Sci. 2005; 46:1201-1207.

7. Auran JD, Koester CJ, Kleiman NJ, et al. Scanning slit confocal microscopic observation of cell morphology and movement within the normal human anterior cornea. Ophthalmology. 1995;102:33-41.

8. Asbell PA, Kamenar T. The response of Langerhans cells in the cornea to herpetic keratitis. Curr Eye Res. 1987;6:179-182.

9. Hazlett LD, McClellan SM, Hume EB, Dajcs JJ, O’Callaghan RJ, Willcox MD. Extended wear contact lens usage induces Langerhans cell migration into cornea. Exp Eye Res. 1999;69:575-577.

10. Zhivov A, Stave J, Vollmar B, Guthoff R. In vivo confocal microscopic evaluation of Langerhans cell density and distribution in the normal human corneal epithelium. Graefes Arch Clin Exp Ophthalmol. 2005;243:1056-1061.

11. Tavakoli M, Boulton AJ, Efron N, Malik RA. Increased Langerhan cell density and corneal nerve damage in diabetic patients: role of immune mechanisms in human diabetic neuropathy. Cont Lens Anterior Eye. 2011;34:7-11.

12. Zhivov A, Stave J, Vollmar B, Guthoff R. In vivo confocal microscopic evaluation of Langerhans cell density and distribution in the corneal epithelium of healthy volunteers and contact lens wearers. Cornea. 2007;26:47-54.

13. Efron N, Al-Dossari M, Pritchard N. Confocal microscopy of the bulbar conjunctiva in contact lens wear. Cornea. 2010;29:43-52.

Clinical Ophthalmology

\section{Publish your work in this journal}

Clinical Ophthalmology is an international, peer-reviewed journal covering all subspecialties within ophthalmology. Key topics include: Optometry; Visual science; Pharmacology and drug therapy in eye diseases; Basic Sciences; Primary and Secondary eye care; Patient Safety and Quality of Care Improvements. This journal is indexed on
14. Zhivov A, Blum M, Guthoff R, Stachs O. Real-time mapping of the subepithelial nerve plexus by in vivo confocal laser scanning microscopy. Br J Ophthalmol. 2010;94:1133-1135.

15. Sweeney DF. Clinical signs of hypoxia with high-Dk soft lens extended wear: is the cornea convinced? Eye Contact Lens. 2003;29:S22-S25.

16. Dart JKG, Radford CF, Minassian D, Verma S, Stapleton F. Risk factors for microbial keratitis with contemporary contact lenses: a case-control study. Ophthalmology. 2008;115:1647-1654.

17. Szczotka-Flynn L, Diaz M. Risk of corneal inflammatory events with silicone hydrogel and low dk hydrogel extended contact lens wear: a meta-analysis. Optom Vis Sci. 2007;84:247-256.

18. Chalmers RL, Keay L, Long B, Bergenske P, Giles T, Bullimore MA. Risk factors for contact lens complications in US clinical practices. Optom Vis Sci. 2010;87:725-735.

19. Levey SB, Cohen EJ. Methods of disinfecting contact lenses to avoid corneal disorders. Surv Ophthalmol. 1996;41:245-251.

20. Andrasko G, Ryen K. Corneal staining and comfort observed with traditional and silicone hydrogel lenses and multipurpose solution combinations. Optometry. 2008;79:444-454.

21. Garofalo RJ, Dassanayake N, Carey C, Stein J, Stone R, David R. Corneal staining and subjective symptoms with multipurpose solutions as a function of time. Eye Contact Lens. 2005;31:166-174.

22. Jones L, MacDougall N, Sorbara LG. Asymptomatic corneal staining associated with the use of balafilcon silicone-hydrogel contact lenses disinfected with a polyaminopropyl biguanide-preserved care regimen. Optom Vis Sci. 2002;79:753-761.

23. Paugh JR, Nguyen AL, Hall JQJ, et al. A preliminary study of silicone hydrogel lens material and care solution bioincompatibilities. Cornea. 2011;7:772-779.

24. Warburton K, Noble-Wang J, Henry B, et al. Absorption of alexidine by contact lenses and lens cases and its effect on disinfection activity against Fusarium solani (Poster Q-426). American Society of Microbiology, 107th General Meeting, Toronto Canada, May 21-25, 2007.

25. Shoff ME, Brown JN, Lucas AD, Hitchins VM. The effects of contact lens and lens cases on disinfection activity in multipurpose contact lens solutions against S. aureus [Poster I-1736]. American Society for Microbiology, 110th General Meeting, San Diego, CA, May 22-27, 2010.

26. Rosenthal RA, Dassanayake NL, Schlitzer RL, Schlech BA, Meadows DL, Stone RP. Biocide uptake in contact lenses and loss of fungicidal activity during storage of contact lenses. Eye Contact Lens. 2006;32:262-266.

27. Dassanayake NL, Garofalo R, Carey C, David R, Meadows DL, Stone RP. Correlating biocide uptake and release profiles with corneal staining and subjective symptoms. Invest Ophthalmol Vis Sci. 2005; 46:915.

28. Rogers R. In vitro and ex vivo wettability of hydrogel contact lenses (Master of Science thesis). Ontario, Canada: University of Waterloo; 2006. Available at: http://uwspace.uwaterloo.ca/bitstream/10012/2974/1/ rrogers2006.pdf. Accessed November 16, 2011.

\section{Dovepress}

PubMed Central and CAS, and is the official journal of The Society of Clinical Ophthalmology (SCO). The manuscript management system is completely online and includes a very quick and fair peer-review system, which is all easy to use. Visit http://www.dovepress.com/ testimonials.php to read real quotes from published authors. 